Etant donnée la structure anatomique de ce Rongeur, il lui est possible de saisir par le dos un poisson incapable de se défendre et de fuir, mais il ne pourra jamais capturer celui qui, d'un coup de queue, a vite fait de gagner du champ. S'il mangeait dans nos étangs les poissons malades ou sans défense, nous devrions nous en réjouir ; il ne ferait qu'aider la sélection naturelle qui ne tolère que les forts.

Une expérience avec le virus de l'Institut Pasteur démontre que le Rat musqué se rapproche du Surmulot ou du Campagnol, puisque, comme ces derniers, il est tué par la maladie transmise. Par contre le Ragondin en absorbe impunément. La scille même, très toxique pour les Rats, lui donne tout au plus quelque colique. C'est une preuve que, dans l'échclle zoologique, le Ragondin n'a rien du Rat.

\title{
Conclusion.
}

It est incontestable que le Rat musqué, implanté sur notre territoirc, doit être limité et détruit autant que possible en raison de ses inconvénients. Contre le Ragondin il n'existe aucun grief démonstratif et le temps ne fera que confirmer ce que nous soutenons depuis trois ans en faveur de ce nouveau rongeur utile aux étangrs et à !a pisciculture.

\section{L'EXTRAGTION DES TOURBETTES DANS LES ÉTANGS}

\author{
Par M. Henri hanUS \\ Pisciculteur à Florent (Marne)
}

En Argonne, on nomme tourbettes les touffes très compactes d'une cer. taine espèce de Laiche que les botanistes appellent Carex stricta Good. (famille des Cypéracées).

Quand le terrain Ieur convient, elles croissent très rapidement dans les étangs peu profonds et peuvent, en quelques années, arriver à couvrir presque complètement le sol. Alors le poisson n'a plus ni paroours ni nourriture et ne peut se défendre contre ses ennemis qui trouvent des repaires de tout repos dans ces buttes. En outre, au moment des pêches, sur le peu qui reste on en perd souvent encore, car entre les tourbettes se forment des poches où Carpes et Tanches se réfugient et où on les retrouve mortes.

En 1931, j'ai fait extraire ces plantes parasites dans un étang de forêt dit: "Les Epinettes " et en ai été récompensé par une belle pêche.

Un autre étang: "La Dame " était complètement envahi ; j'y avais fait successivement, en réempoissonnement, deux pêches creuses, ce qui m’a 
décidé à le netloyer cotte année. L'élang en question se trouve au bord de la route de Givry-en-Argonne à Clermontois, dans le département de la Marne, juste en face de l'embranchement conduisant à Belval, où sont les étangs de M. Maurice Pol-Rogen qui virent, en I926, le premier concours d'appareils faucardeurs.

Mes ouvriers ont employé, tout simplement, de fortes faulx à moisson après en avoir coupé le talon et y avoir fait river deux poignées en fer rond de 15 millimètres de diamètre, l'une dans le prolongement de la verge, l'autre posée perpendiculairement à 10-15 centimètres de la précédente. Ces poignées ont environ $3 \tilde{5}$ centimètres de largeur et sont recourbées vers le haut pour que l'ouvrier qui les lient en main ait moins à se baisser et ne se blesse pas au contact du sol (fig. io).

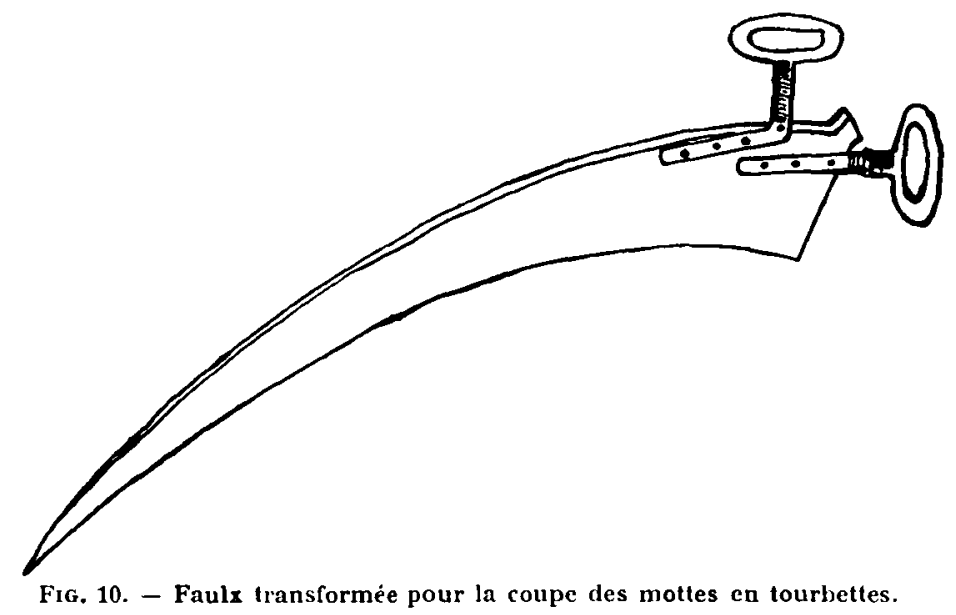

La faulx est manœuvrée horizontalement et il importe qu'clle tranche le plus bas possible. '́n aide est nécessaire qui tire la motte au moyen d'un croc à fumier pour faciliter la coupe. Lorsque les tourbettes sont trop larges, on les tranche d'abord verticalement.

Ce fut un travail pénible, fastidicux. On ne déblayait pas un grand espace chaque jour car ill fallait, après les avoir sectionnées, transporter en civière les mottes sur les bords de l'étangr. Leur masse s'est élevée à plusieurs centaines de mètres cubes.

Des bouleaux et trembles rachitiques avaient poussé sur les touffes, mais leurs racines n'atteignant qu'exceptionnellement le fond de l'étang n'ont pas été gênantes.

Le travail, consciencieusement fait, est revenu à plus de r.ooo francs l'hectare. Il va être suivi d'une culture au brabant et, vers les 15-20 Octobre, la bonde sera fermée, car l'étang "La Dame " n'est alimenté que par les eaux de pluie ( $\mathbf{r}$ ).

(1) Au sujet de l'extraction des tourbettes, voir Bulletin, $\mathrm{n}^{\circ} \mathrm{I} 7$, Novembre ${ }^{239}$, p. 108 . 